\title{
Facet-Dependent Photodegradation of Methylene Blue by Hematite Nanoplates in Visible Light
}

Meirong Zong ${ }^{\dagger,+}$, Duo Song ${ }^{\ddagger}$ Xin Zhang ${ }^{*+}$, Xiaopeng Huang ${ }^{\ddagger}$, Xiancai Lu ${ }^{* \dagger}$ and Kevin M. Rosso ${ }^{*}$

† School of Earth Sciences and Engineering, Nanjing University, Nanjing, Jiangsu 210023, China

$¥$ Physical \& Computational Science Directorate, Pacific Northwest National Laboratory, Richland, Washington 99354, United State

\section{Corresponding Authors}

E-mail: Xin.Zhang@pnnl.gov (X.Z); xcljun@nju.edu.cn (L.X.); Kevin.Rosso@pnnl.gov (K.M.R.) 


\section{Supporting Information Summary}

No. of pages: 17 No. of Figures: $12 \quad$ No. of tables: 1

Page S3: Experimental data fitting models

Page S5: Figure S1. Hydroxyl-terminated (001) hematite surface(A) and (012) hematite surface (B). The crystal structure of hematite entails hexagonal close-packing (hcp) of $\mathrm{O}^{2-}$ along the [001] direction and $\mathrm{Fe}^{3+}$ fill 2/3 of the available octahedral interstices. Each $\mathrm{Fe}$ atom coordinate six $\mathrm{O}$ atoms and each $\mathrm{O}$ atom coordinate four $\mathrm{Fe}$ atoms.

Page S6: Figure S2. AFM topographic images of hematite nanoparticles (HNP1) (A, $\mathrm{B}, \mathrm{C})$, and illustrations of the size and thicknesses analysis method (B, D). The AFM images were analyzed by NanoScope Analysis version 1.5.

Page S7: Figure S3. The structural modeling and formula of methylene blue.

Page S8: Figure S4. (A) The UV-VIS Absorption spectrum of methylene blue. (B) Calibration curves are obtained with standard Methylene Blue solutions.

Page S9: Figure S5. XRD patterns(A) and Raman spectra(B) of the two kinds hematite nanoplates.

Page S10: Figure S6. A, the characteristic peaks of Raman spectra of NaAc. B, Raman spectra of the two kinds hematite nanoplates. C and D were the NaAc characteristic peaks places.

Page S11: Figure S7. The size distribution of HNP1 and HNP2. Sixty hematite nanoparticles were counted for each sample.

Page S12: Figure S8. Point-of-zero-charge estimates for HNP1 and HNP2 based upon zeta potential measurements.

Page S13: Figure S9. Comparison of adsorption isotherm models of Temkin isotherm (A), Langmuir (B), and no nonlinear fitting (C).

Page S14: Figure S10. The MB adsorption linear plot of Pseudo-second-order kinetics fitting (A) and no nonlinear fitting(B).

Page S15: Figure S11. Degradation of methylene blue over HNPs under different reaction conditions with visible light. The catalyst concentration of hematite nanoparticles was $0.5 \mathrm{~g} \cdot \mathrm{L}^{-1}$. The dye concentration of MB was $10 \mathrm{mg} \cdot \mathrm{L}^{-1}$. The dark adsorption time was 2 hours (120 mins), and the photodegradation reaction was 7 hours.

Page S16: Figure S12. The no nonlinear fitting for the MB photodegradation by HNPs. 
Page S17: Table S1. The size and thickness analysis and exposed facets ratio of HNP1 and HNP2.

\section{Experimental data fitting models}

\section{Models of equilibrium adsorption isotherm.}

Temkin isotherm model can be expressed by,

$\mathrm{q}_{\mathrm{e}}=\mathrm{B} \ln \mathrm{A}+\mathrm{B} \ln \mathrm{C}_{\mathrm{e}}$

where $\mathrm{B}=\mathrm{RT} / \mathrm{b}, \mathrm{b}\left(\mathrm{J} \mathrm{mol}^{-1}\right)$ is the Temkin constant related to adsorption heat, $\mathrm{T}(\mathrm{K})$ is the absolute temperature, $\left.\mathrm{R}\left(8.314 \mathrm{~J} \mathrm{~mol}^{-1} \mathrm{~K}^{-1}\right)\right)$ is the gas constant, and $\mathrm{A}\left(\mathrm{L} \mathrm{g} \mathrm{g}^{-1}\right)$ is the Temkin isotherm constant. B and A can be calculated from the slope and intercept of the plot of $\mathrm{q}_{\mathrm{e}}$ against $\ln \mathrm{C}_{\mathrm{e}}$.

Langmuir isotherm model is based on the assumption that each active site can only hold one adsorbate molecule. The linear equation given by the Langmuir isotherm is expressed as,

$\mathrm{C}_{\mathrm{e}} / \mathrm{q}_{\mathrm{e}}=1 /\left(\mathrm{q}_{0} \mathrm{~b}\right)+\mathrm{C}_{\mathrm{e}} / \mathrm{q}_{0}$

where $\mathrm{q}_{\mathrm{e}}\left(\mathrm{mg} \mathrm{m}^{-2}\right)$ and $\mathrm{C}_{\mathrm{e}}\left(\mathrm{mg} \mathrm{L}^{-1}\right)$ are the amount of adsorbed $\mathrm{MB}$ onto hematite nanoparticles and $\mathrm{MB}$ concentration at equilibrium, respectively, $\mathrm{q}_{0}\left(\mathrm{mg} \mathrm{m}^{-2}\right)$ is the maximum amount of MB adsorbed per unit mass of hematite nanoparticles, and $b(\mathrm{~L}$ $\mathrm{mg}^{-1}$ ) is a constant related to the adsorption energy.

Freundlich expression model given by:

$$
\ln q_{\mathrm{e}}=\ln K_{f}+1 / \mathrm{n} \ln \mathrm{C}_{\mathrm{e}}
$$

Where $q_{\mathrm{e}}$ is the solid-phase adsorbate concentration at equilibrium $\left(\mathrm{mg} \mathrm{m}^{-2}\right), \mathrm{C}_{\mathrm{e}}$ is the aqueous-phase adsorbate concentration at equilibrium $\left(\mathrm{mg} \mathrm{L}^{-1}\right), K_{f}\left(\mathrm{mg} \mathrm{m}^{-2}\right)\left(\mathrm{L} \mathrm{mg}^{-1 / n}\right.$ is a Freundlich constant indicative of the relative adsorption capacity of the adsorbent and $1 / \mathrm{n}$ is the heterogeneity factor.

Models of adsorption kinetics. 
The pseudo-first-order model can be expressed by the following linear form, $\ln \left(\mathrm{q}_{\mathrm{e}}-\mathrm{q}_{\mathrm{t}}\right)=\ln \mathrm{q}_{\mathrm{e}}-\mathrm{kt}$

where $\mathrm{q}_{\mathrm{e}}$ and $\mathrm{q}_{\mathrm{t}}\left(\mathrm{mg} \mathrm{m}^{-2}\right)$ are the amounts of adsorbed MB at equilibrium and at time $\mathrm{t}$, respectively, $\mathrm{k}\left(\mathrm{min}^{-1}\right)$ is pseudo-first-order rate constant, and $\mathrm{t}(\mathrm{min})$ is contact time. $\mathrm{k}$ can be determined from the slope of the plot of $\ln \left(q_{e}-q_{t}\right)$ versus $t$.

The pseudo-second-order relation given as:

$$
\mathrm{t} / \mathrm{q}_{\mathrm{t}}=1 /\left(K_{l} \cdot \mathrm{q}_{\mathrm{e}}^{2}\right)+\mathrm{t} / \mathrm{q}_{\mathrm{e}}
$$

where $\mathrm{t}(\mathrm{min})$ is the adsorption reaction time, $\mathrm{q}_{\mathrm{t}}\left(\mathrm{mg} \mathrm{m}^{-2}\right)$ is the adsorbed amount at time $\mathrm{t}, \mathrm{q}_{\mathrm{e}}\left(\mathrm{mg} \mathrm{m}^{-2}\right)$ is the equilibrium amount adsorbed per gram of adsorbent, and $K_{l}\left(\mathrm{~g} \mathrm{mg}^{-1}\right.$ $\min ^{-1}$ ) is the adsorption rate constant.

\section{Degradation model}

\section{Langmuir-Hinshelwood pseudo-first-order model:}

$$
-\ln \left(\mathrm{C} / \mathrm{C}_{0}\right)=K_{2} \mathrm{t}
$$

Where $K_{2}\left(\mathrm{~h}^{-1}\right)$ is the pseudo-first-order degradation rate constant, and $\mathrm{t}(\mathrm{h})$ is the specific time. The kinetics were measured by plotting the $-\ln \left(\mathrm{C} / \mathrm{C}_{0}\right)$ versus $\mathrm{t}$.

Nonlinear fitting. The Nonlinear fitting was Calculated by the nonlinear curve fit in the Origin software. 


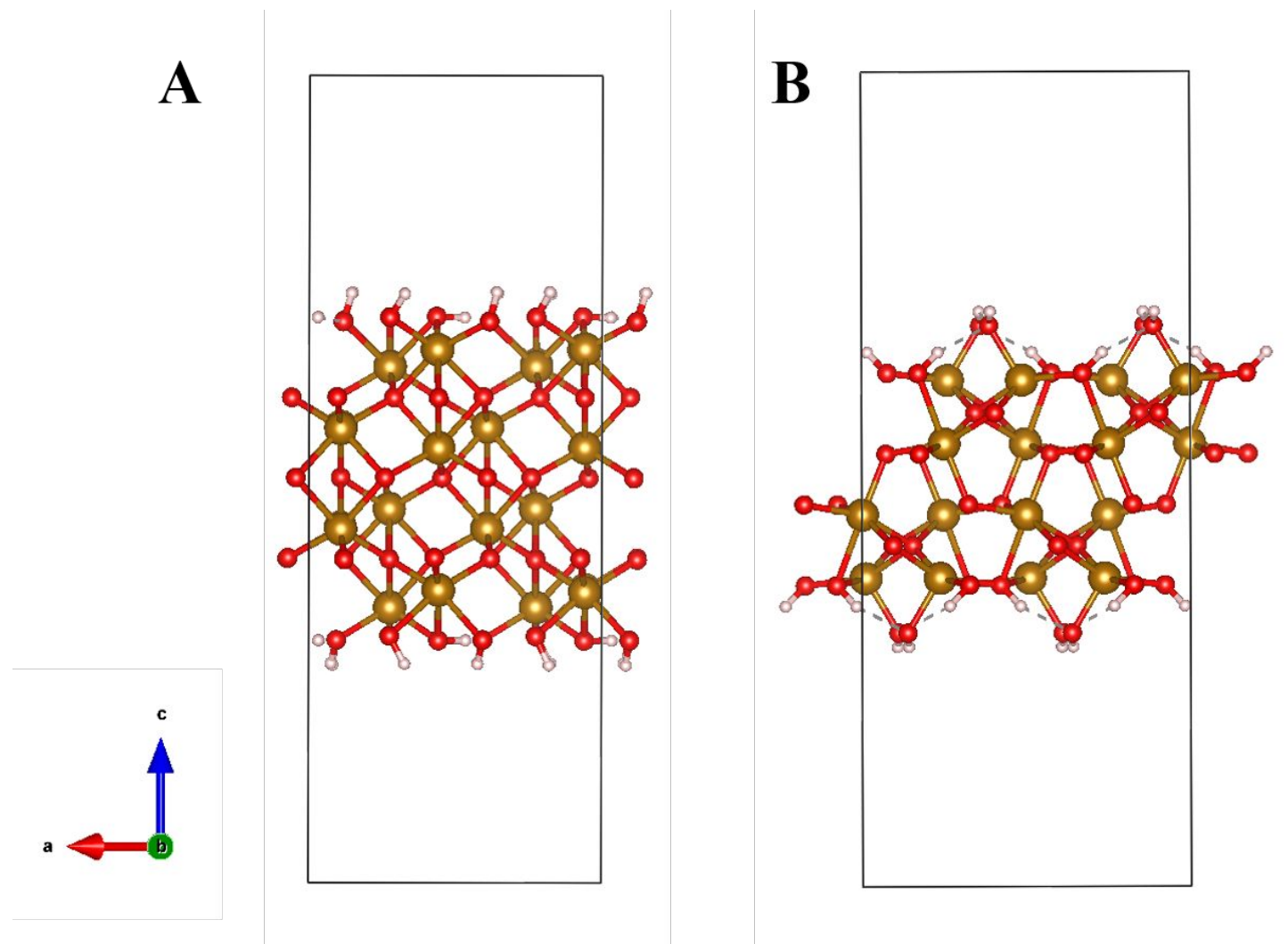

Figure S1. Hydroxyl-terminated (001) hematite surface(A) and (012) hematite surface (B). The crystal structure of hematite entails hexagonal close-packing (hcp) of $\mathrm{O}^{2-}$ along the [001] direction and $\mathrm{Fe}^{3+}$ fill 2/3 of the available octahedral interstices. Each $\mathrm{Fe}$ atom coordinate six $\mathrm{O}$ atoms and each $\mathrm{O}$ atom coordinate four $\mathrm{Fe}$ atoms. 


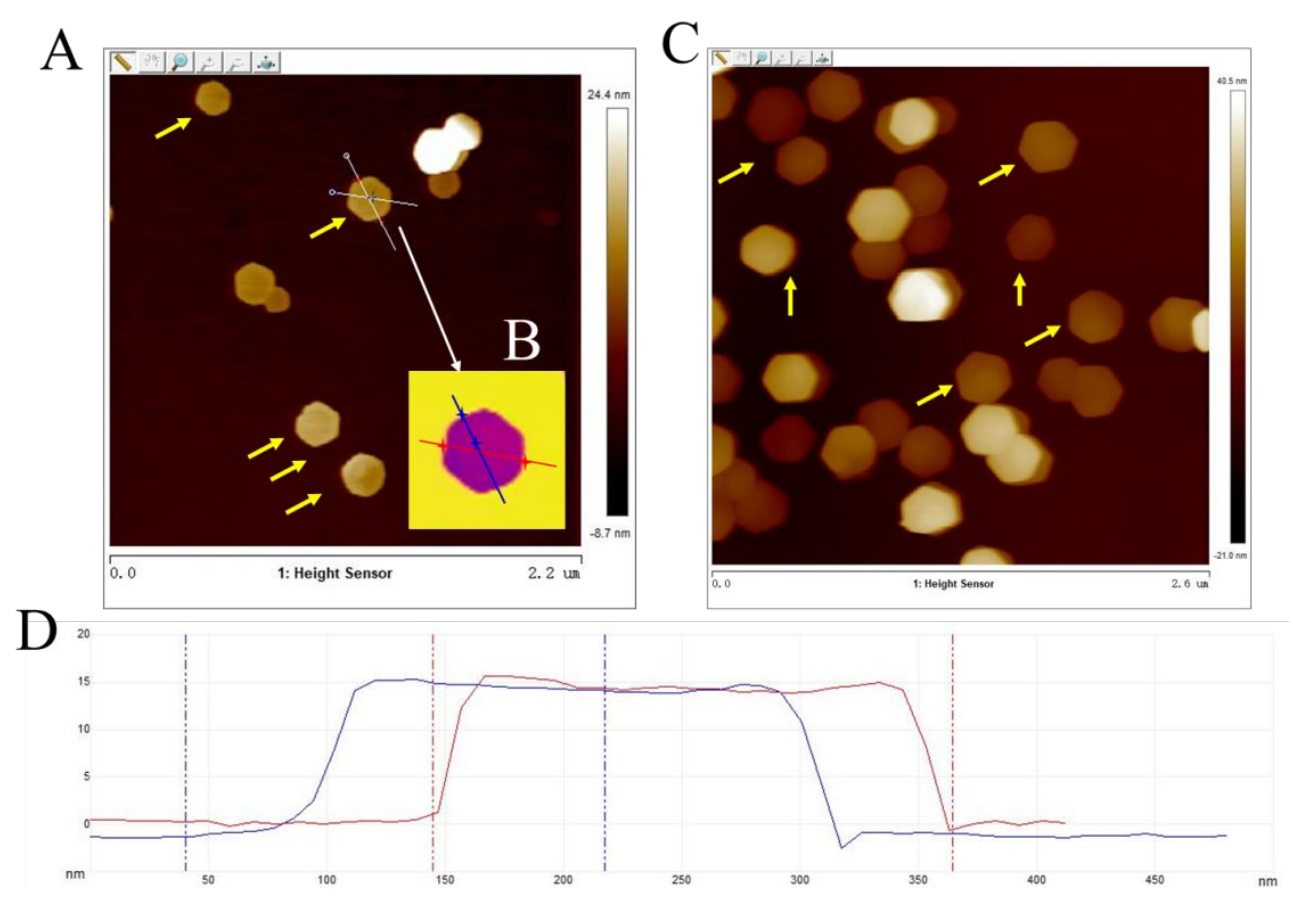

Figure S2. AFM topographic images of hematite nanoparticles (HNP1) (A, B, C), and illustrations of the size and thicknesses analysis method (B, D). The AFM images were analyzed by NanoScope Analysis version 1.5. 

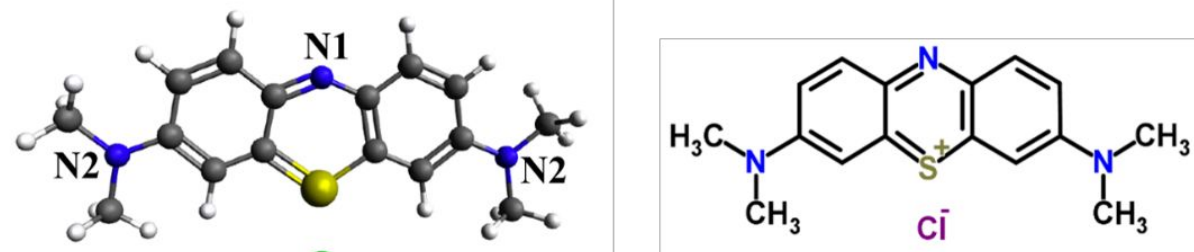

Figure S3. The structural modeling and formula of methylene blue. 
A

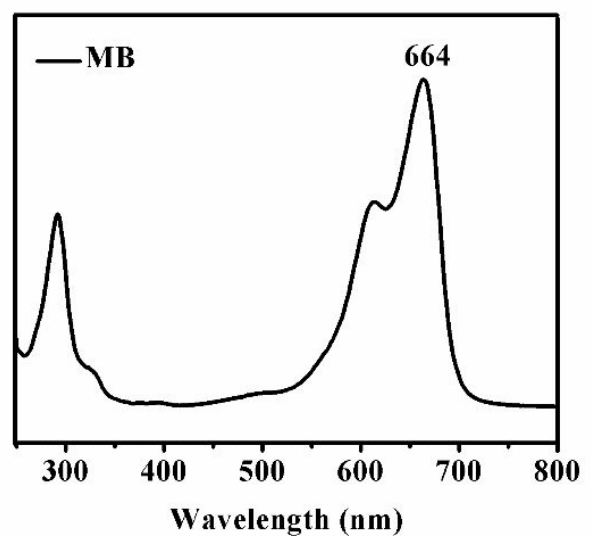

B

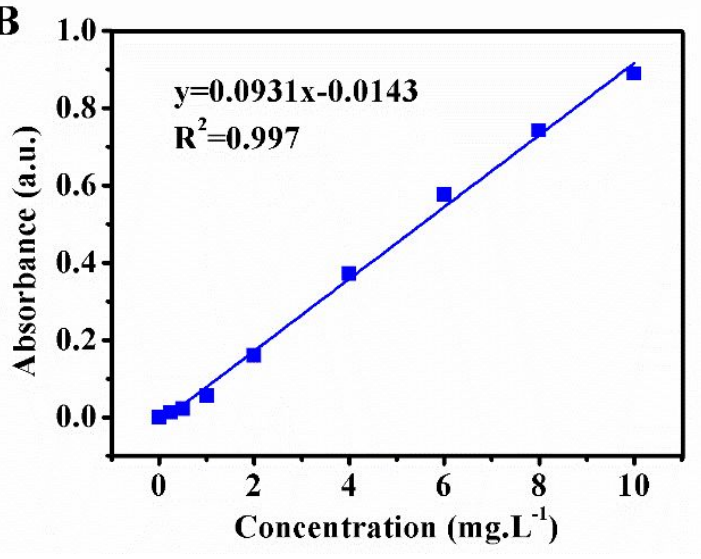

Figure S4. (A) The UV-VIS Absorption spectrum of methylene blue. (B) Calibration curves are obtained with standard Methylene Blue solutions. 
A

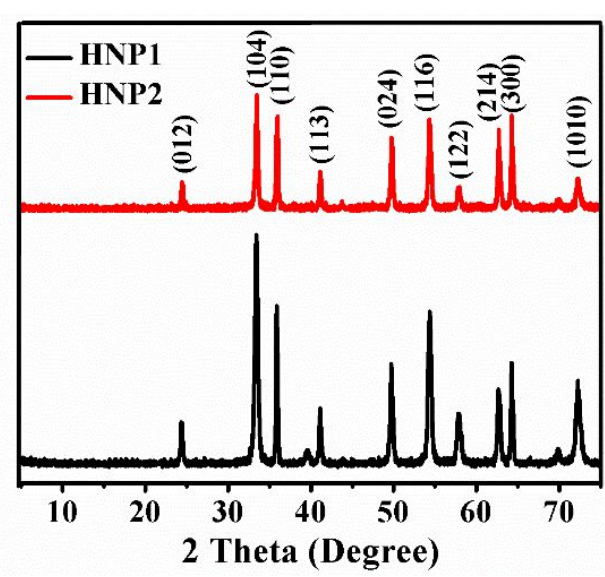

B

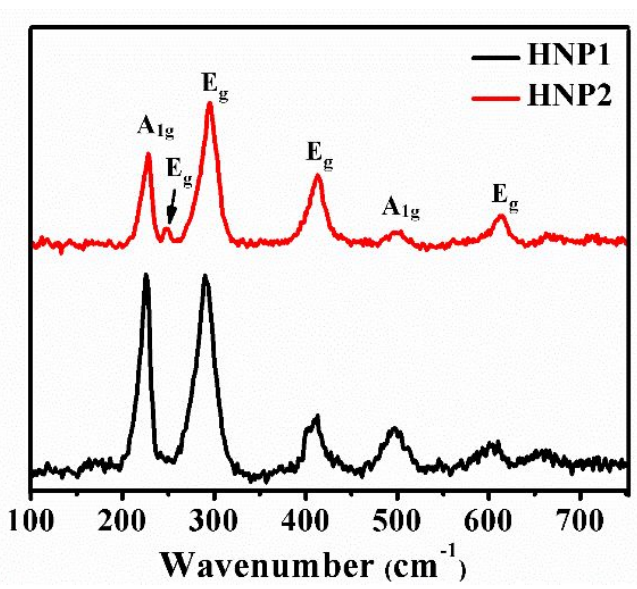

Figure S5. XRD patterns(A) and Raman spectra(B) of the two kinds hematite nanoplates. 
A

Sodium acetate(127-09-3) Raman

Product Basic Information:

Product Name:Sodium acetate

CAS: $\quad 127-09-3$

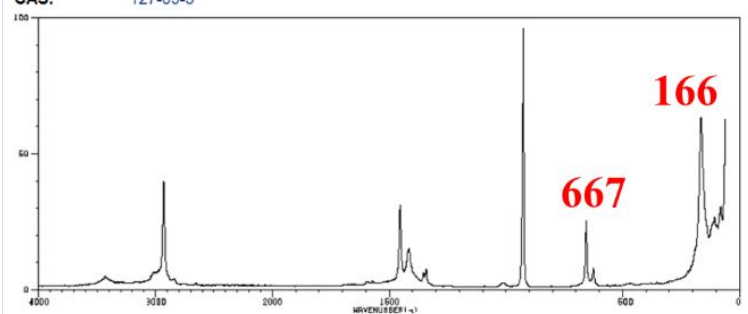

SODIUI1 ACETATE
SDESNO $=2981 \quad \mathrm{C}_{2} \mathrm{H}_{3} \mathrm{NAO}_{2} \mathrm{~K}_{2} \mathrm{H}_{2} \mathrm{O} \quad \mathrm{RH}-01-00870: 4880 \mathrm{O} \cdot 20 \mathrm{OH}$. POHDER

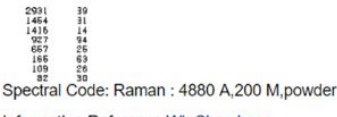

B

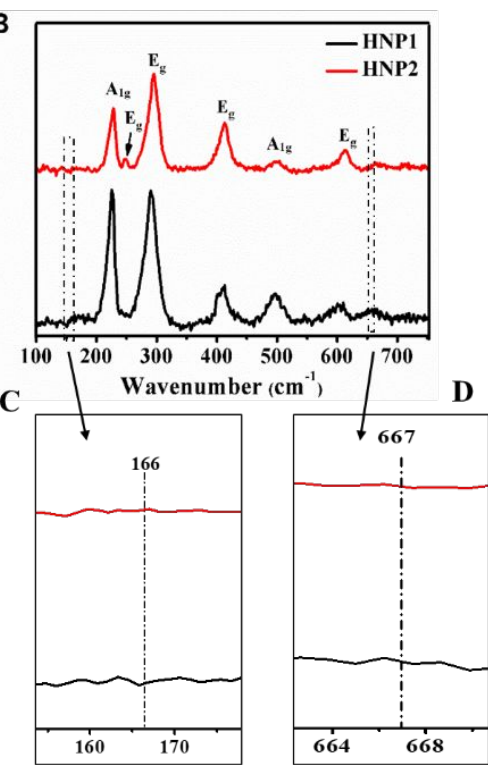

Figure S6. A, the characteristic peaks of Raman spectra of NaAc. B, Raman spectra of the two kinds hematite nanoplates. $\mathrm{C}$ and $\mathrm{D}$ were the NaAc characteristic peaks places. 

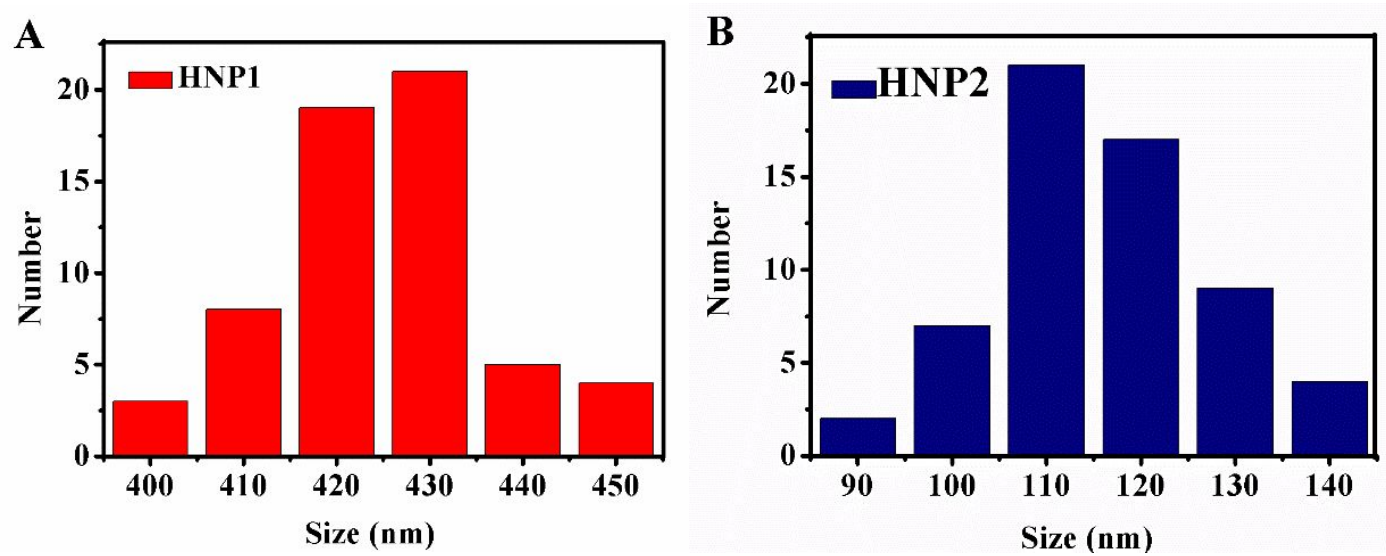

Figure S7. The size distribution of HNP1 and HNP2. Sixty hematite nanoparticles were counted for each sample. 


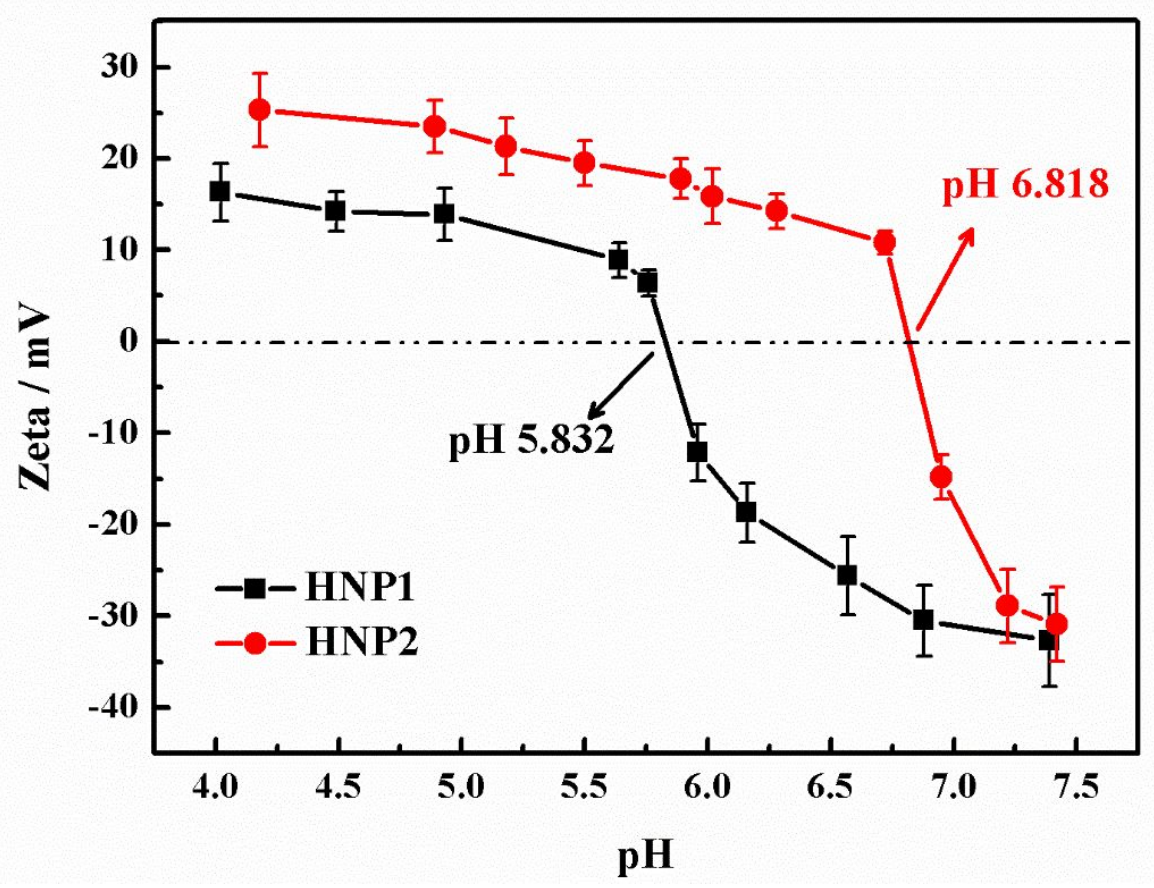

Figure S8. Point-of-zero-charge estimates for HNP1 and HNP2 based upon zeta potential measurements. 

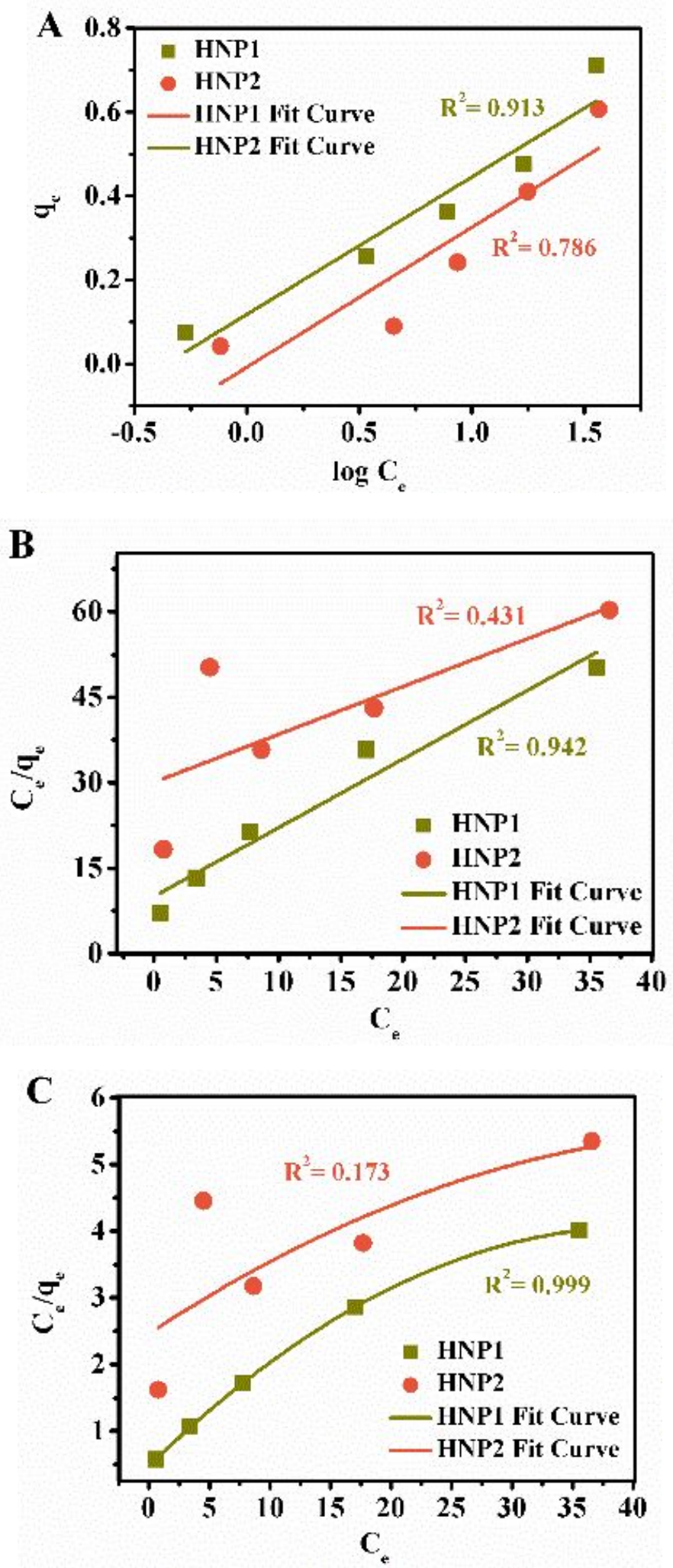

Figure S9. Comparison of adsorption isotherm models of Temkin isotherm (A), Langmuir (B), and no nonlinear fitting $(\mathrm{C})$. 

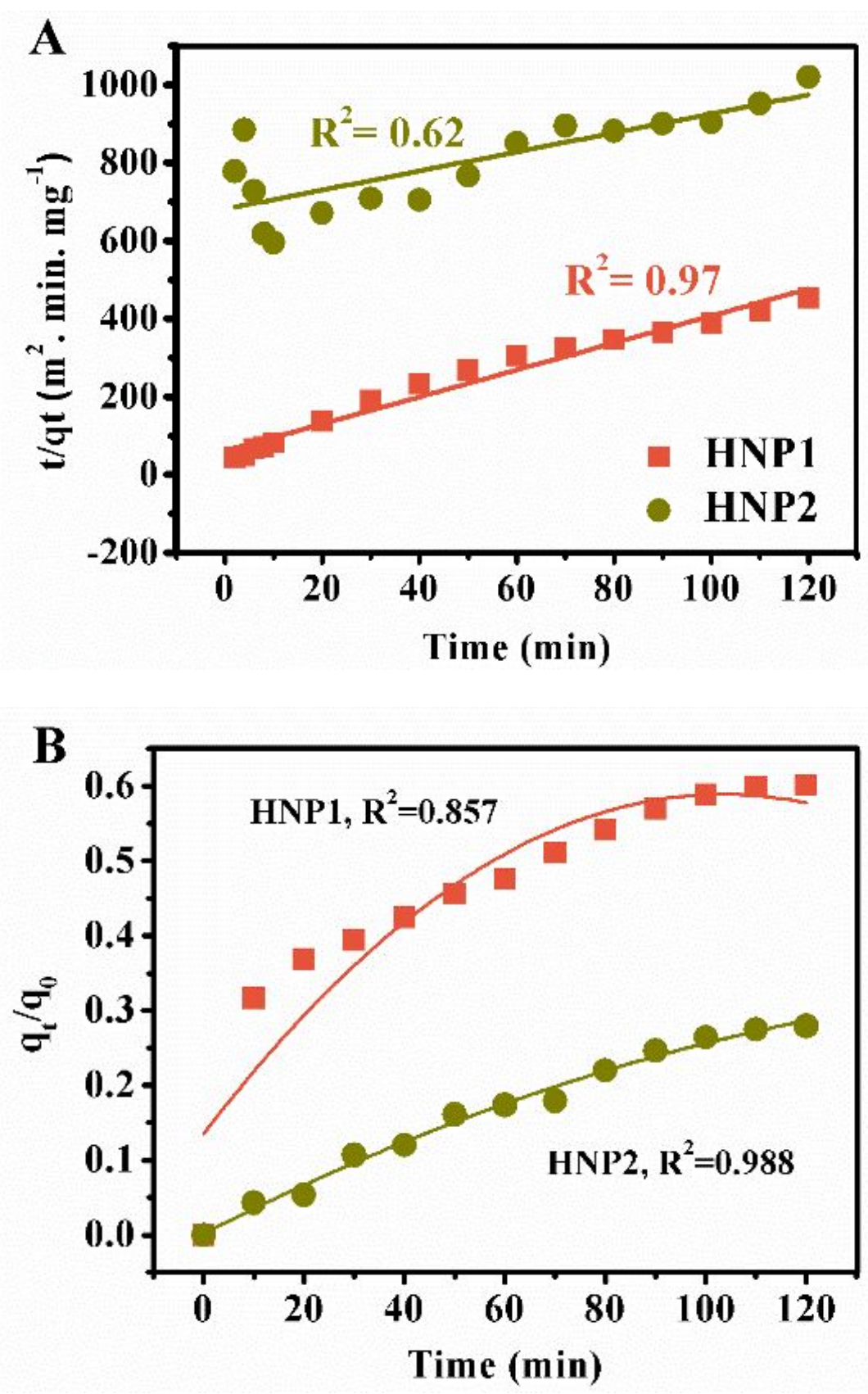

Figure S10. The MB adsorption linear plot of Pseudo-second-order kinetics fitting (A) and no nonlinear fitting(B). 


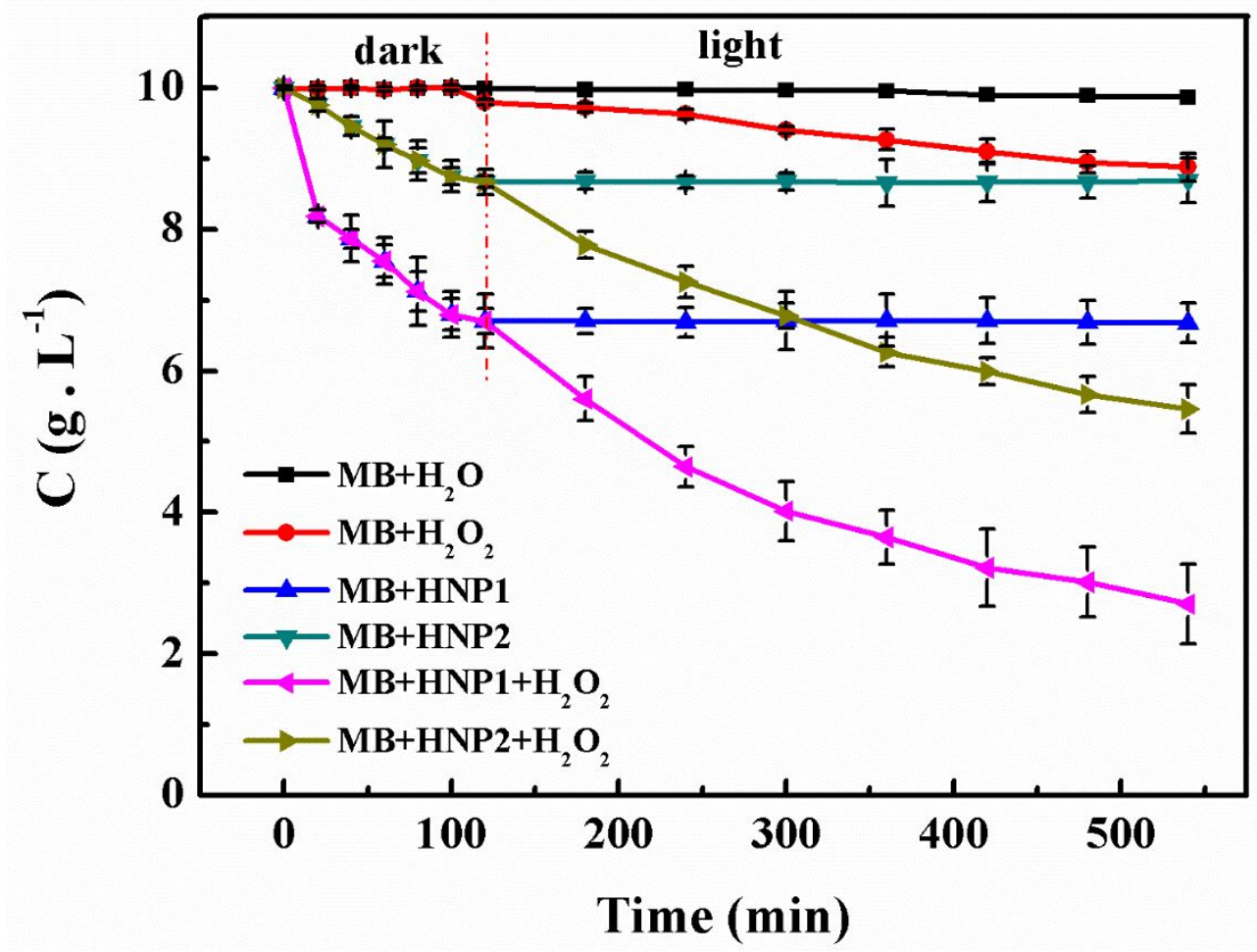

Figure S11. Degradation of methylene blue over HNPs under different reaction conditions with visible light. The catalyst concentration of hematite nanoparticles was $0.5 \mathrm{~g} \cdot \mathrm{L}^{-1}$. The dye concentration of MB was $10 \mathrm{mg} \cdot \mathrm{L}^{-1}$. The dark adsorption time was 2 hours (120 mins), and the photodegradation reaction was 7 hours. 


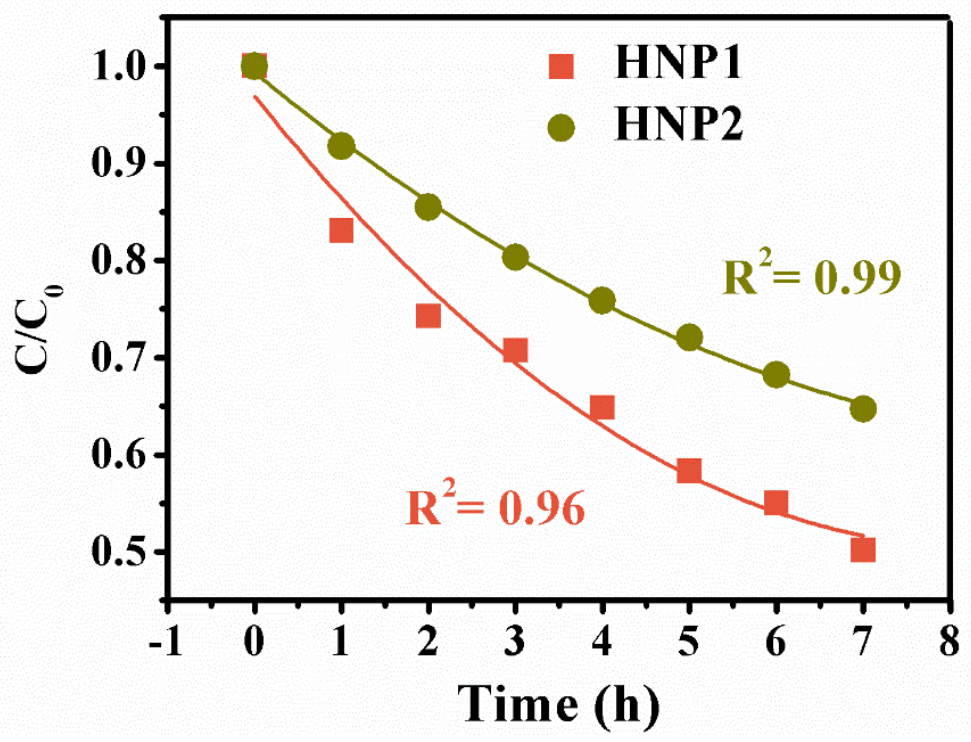

Figure S12. The no nonlinear fitting for the MB photodegradation by HNPs. 
Table S1. The size and thickness analysis and exposed facets ratio of HNP1 and HNP2.

\begin{tabular}{cccc}
\hline Sample & Size & Thickness & Ratio of Surface area \\
& $(\mathrm{nm})$ & $(\mathrm{nm})$ & $(001) /(012)$ \\
\hline HNP1 & $425 \pm 30$ & $22 \pm 4$ & $7.62 \pm 0.84$ \\
HNP2 & $120 \pm 12$ & $27 \pm 5$ & $1.79 \pm 0.15$ \\
\hline
\end{tabular}

Note, 60 particles were randomly analyzed. 